University of Nebraska - Lincoln

DigitalCommons@University of Nebraska - Lincoln

Faculty Publications, College of Journalism \& Journalism and Mass Communications, College Mass Communications

2012

\title{
The Process of General Education Reform from a Faculty Perspective: A Grounded Theory Approach
}

Frauke Hachtmann

University of Nebraska - Lincoln, fhachtmann1@unl.edu

Follow this and additional works at: https://digitalcommons.unl.edu/journalismfacpub

Part of the Higher Education Administration Commons

Hachtmann, Frauke, "The Process of General Education Reform from a Faculty Perspective: A Grounded Theory Approach" (2012). Faculty Publications, College of Journalism \& Mass Communications. 69. https://digitalcommons.unl.edu/journalismfacpub/69

This Article is brought to you for free and open access by the Journalism and Mass Communications, College of at DigitalCommons@University of Nebraska - Lincoln. It has been accepted for inclusion in Faculty Publications, College of Journalism \& Mass Communications by an authorized administrator of DigitalCommons@University of Nebraska Lincoln. 


\title{
The Process of General Education Reform from a Faculty Perspective: A Grounded Theory Approach
}

\author{
Frauke Hachtmann
}

General education is firmly grounded in the modern American collegiate experience. Currently, more than 85 percent of colleges and universities in the United States require all of their students to complete some general education requirements (Black Duesterhaus, 2003). Rooted in the European model of classic education, which includes the study of classic literary works, philosophy, foreign languages, rhetoric, and logic, the U.S. model is characterized by an additional layer of practicality (Black Duesterhaus, 2003). Whereas the European model was designed to prepare students for a handful of professional careers mostly in law and medicine, the U.S. model aspires to prepare students for a larger variety of professions. Therefore, students in the United States are exposed to a more selective model of general education when compared with the classic European model upon which it was built. The major forces of general education reform in the United States were a response to societal needs during the midand late twentieth century, as well as more specialized demands from industry to equip students with skills for the professional world.

The purpose of general education shifted to add an element of practical training in a specific discipline through a survey of courses that promoted critical thinking and an awareness of the world in which students worked and lived 
(Black Duesterhaus, 2003). According to a survey among representatives of the Association of American Colleges and Universities (AAC\&U), more than half its members indicated that general education has increased as a priority at their institutions, and almost 90 percent of higher education institutions are currently either assessing or modifying their general education programs (Hart Research Associates, 2009). However, according to the AAC\&U, 95 percent of general education reform failures are directly related to failure in process.

In 2005, the chancellor of a large, doctoral/research-extensive land-grant university in the Midwest called for a general education reform because the current curriculum was viewed as complicated and unattractive for students transferring from one college to another and from other universities (Kean, Mitchell, \& Wilson, 2008). After much planning, discussions, and voting in each of the institution's undergraduate colleges, the university launched a new, outcomes-based general education program in fall 2009 , replacing the previous subject-based program. The program consists of ten carefully constructed student-learning outcomes that all undergraduate students must achieve before graduating. Over the course of two and a half years, faculty developed a set of outcomes that reflects what they believe graduates ought to know as they embark on their careers in the twenty-first century. In addition to the ten outcomes, faculty also developed a set of governing documents that stipulate the structural criteria and the process for reviewing and certifying an initial set of outcomes-based general education courses, as well as the new program's governance and assessment structure.

General education reform would not be possible without strong administrative and faculty leadership. The institution was hoping that the development and implementation of the new general education program would result in a cultural shift away from a subject-based program to an outcomes-based program that is student-centered as opposed to teacher-centered. However, it was not clear whether faculty were aware of this shift. Understanding the factors that affect change and how faculty respond to change is important for the successful implementation of change (Noll, 200I). Anchoring change in an organization's culture is a key ingredient in sustainable transformation (Kotter, 1998). Therefore, this study examined the organizational culture of the institution from a faculty perspective at the time of the development and implementation of the new outcomes-based general education program.

The purpose of this grounded theory case study was to develop a theory for institutional change that explains the process and implementation of a new general education program from the faculty perspective at a large, doctoral/researchextensive university in the Midwest. No theory currently exists that explains the process of general education reform at a doctoral/research-extensive university. 
The study was guided by the following two central research questions: What is the theory that explains the process of the development and implementation of general education reform at this particular institution? How did it unfold?

In a grounded theory study the steps are to identify the central phenomenon, the causal conditions, the intervening conditions, and the strategies and consequences (Strauss \& Corbin, 1998). Therefore, during the initial stages data collection sought to answer the following subquestions:

I. What was central to the process? (core phenomenon)

2. What influenced or caused this phenomenon to occur? (causal conditions)

3. What strategies were employed during the process? (strategies)

4. What effect occurred? (consequences)

\section{Significance}

A study of the process of general education reform at a large, doctoral/researchextensive land-grant institution is important for several reasons. The results add to the existing scholarly research and literature of general education reform because despite the large number of studies describing general education reform at a variety of institutions, no theory currently exists that explains the process of development and implementation of general education reform from a faculty perspective at a public land-grant, research-extensive university. Researchers may use the theoretical propositions of this study and test them quantitatively. The results may also help improve practice, as 89 percent of higher education institutions across the country are currently in the process of assessing or modifying their general education programs (Hart Research Associates, 2009). As faculty are ultimately responsible for curricular change, understanding the theory of the change process could help other institutions to implement effective strategies when revising their general education programs.

This study can also help institutions to implement and sustain outcomesbased general education programs in the long run because it relates organizational culture to the reform process. Tierney (1988) identified five advantages of becoming aware of organizational culture, including (I) an understanding of the conflicts "on the broad canvas of organizational life," (2) recognition of how tensions in the organization are played out in operational and structural issues, (3) making decisions with "keen awareness" of their impact on groups within the institution, (4) understanding the symbolic nature of seemingly instrumental actions, and (5) consideration of why different groups in the organization have different perspectives on how the organization is performing. 
Finally, this study may help institutions that are in the reform process with the selection of faculty to serve on committees that are charged with developing or implementing curricular change. Universities across the nation are faced with tighter budgets and are expected to do more with less. This study addresses the change process of general education, which may provide universities with theoretical propositions that could help them to respond to economical pressures more efficiently and effectively. This research proposes strategies that can be used to design and approve an outcomes-based general education program on a tight timeline.

\section{Literature Review}

A recent survey among AAC\&U administrators indicates that for the majority of member institutions, general education has increased as a priority for their institution. In fact, 89 percent of them are currently in the process of assessing or changing their general education programs (Hart Research Associates, 2009). Despite these efforts, only I8 percent of those member institutions are actually implementing changes adopted in the past five years (Hart Research Associates, 2009). Rhodes (2003) explains that during the last decade of the twentieth century curriculum reform was slowed by three obstacles: the content of the core, student demands, and fragmentation. He recommends that in order to overcome these obstacles, faculty must recapture the curriculum by defining educational goals, priorities, and requirements. While students must be able to make choices as part of their undergraduate experience, the faculty's goal should be "to equip graduates for both employment and life as motivated self-starters, with a thirst for understanding and the discipline and skills to satisfy it" (Rhodes, 2003, p. 94).

Some of the current trends in recent general education reform include (I) an emphasis on the demonstration of broad competencies as opposed to learning goals that focus on the mastery of content, (2) the importance of integrative learning experiences across the curriculum, and (3) a focus on improving learning by improving instructional methods and assessments of student learning (DeZure, 2003). Currently, most undergraduate curricula consist of general education or liberal studies, a major and often minors, and electives in order to ensure breadth of knowledge through distribution requirements and depth of knowledge and skills through the major. However, the goals of learning have changed. Whereas knowledge of disciplinary facts and concepts used to be the emphasis, now the focus of student learning is on broadly defined competencies to ensure that students are well equipped to be responsible citizens and professionals upon graduation. In 2009, 78 percent of AAC\&U member institutions indicated that they had a common set of intended 
learning outcomes for all of their undergraduate students (Hart Research Associates, 2009). Many AAC\&U member institutions indicate that the outcomes they are focusing on are those that employers said they would like to see in college graduates (Hart Research Associates, 2009). One of AAC\&U's most recent initiatives is "Liberal Education and America's Promise" (LeAP), which focuses on the quality of student learning. AAC\&U's (2007) report College Learning for the New Global Century suggests that students should prepare for "twenty-first century challenges" (p. 3) by achieving four essential learning outcomes, including (I) knowledge of human cultures and the physical and natural world, (2) intellectual and practical skills (inquiry and analysis, critical and creative thinking, written and oral communication, quantitative literacy, information literacy, and teamwork and problem solving), (3) personal and social responsibility (civic knowledge and engagement-local and global, intercultural knowledge and competence, ethical reasoning and action, and foundations and skills for lifelong learning), and (4) integrative learning (synthesis and advanced accomplishments across general and specialized studies).

So how should a general education program be revised? Tyler (1949) suggested that four essential questions shape knowledge in the curriculum, including the purpose the curriculum should serve, the experiences the institution and its faculty provide to meet that purpose, the effective organization of the curriculum, and the assessment of learning outcomes. Taba (1962) added that a change in the curriculum reflects a change in the institution and called for faculty to play an integral role in establishing goals and objectives for learning. Her seven-step model includes the following cycle: (I) defining the philosophy of the curriculum, (2) creating a learning environment, (3) delineating intended learning outcomes, (4) designing instruction, (5) delivering instruction, (6) assessing intended outcomes, and (7) improving instructional design. Many different delineations of this basic model have occurred since Taba introduced it, but the basic idea stayed the same (Conrad, 1978; Dressel, 1968). Several scholars added the notion that curriculum is socially constructed, meaning that students, teachers, administrators, and other stakeholders are reflected in its development (Baxter Magolda, 1999; Mentkowski \& Associates, 2000; Ropers-Huilman, 1998).

Increasingly, assessment is becoming a major component of general education programs because the new set of competencies requires measurements of learning that evaluate higher-order critical-thinking skills. In 2009, almost all AAC\&U member institutions indicated that they had specified field-specific learning outcomes in some of their departments, while 65 percent said that they had defined outcomes in all departments. However, only 30 percent of AAC\&U's member institutions indicated that they were conducting assessments of learning outcomes in general education (Hart Research Associates, 2009). 


\section{Method}

A qualitative research design was used for this study because not much was known about the process and implementation of general education reform at doctoral/research-extensive land-grant universities from a faculty perspective (Strauss \& Corbin, 1998). A retrospective grounded theory case study was used to generate a theory about the process of developing and implementing a new general education program, which is a "systematic, qualitative procedure that researchers use to generate a general explanation of a process, action, or interaction among people" (Creswell, 2005, p. 52).

\section{Data Collection Procedures}

Theoretical sampling was used to select participants for the study (Strauss \& Corbin, 1998). The first level of theoretical sampling involved the selection of the site for the study. The institution was selected for this study because it was one of sixteen universities and colleges that the AAC\&U selected to participate in the Greater Expectations Consortium on Quality Education. The initiative exposed key leaders from the institution to new ways of thinking about undergraduate education, which resulted in the development and implementation of a modern general education program focused on student learning and "continuous improvement of the campus learning environment" (Kean et al., 2008, p. 4).

The second level of theoretical sampling involved the selection of the participants, who consisted of a broad range of faculty from all eight undergraduate colleges who had all experienced the process of this particular general education reform. This homogeneous sample included faculty who had the opportunity to vote on the implementation of the new program. Many of the faculty who were approached indicated that they did not know enough about the new general education program and the reform process and decided not to participate, while others did not reply to the initial invitation or follow-up invitation. As with most qualitative studies that use rich, thick descriptions and direct quotes to illustrate emerging themes, complete confidentiality of participants' identities could not be guaranteed. It should be noted that the institution had been engaged in extensive budget cuts during the general education reform process. It is possible that those prospects who decided not to participate were uncomfortable sharing their opinions as part of this study. The homogeneous sample consisted of nineteen participants. After the initial theory was developed, a heterogeneous sample was included, which included faculty who were very actively involved in developing and implementing the new general education program by serving on one or more of the planning committees or other faculty groups that were involved in curriculum matters. 
TABLE I Characteristics of participants

\begin{tabular}{|l|c|c|c|c|c|c|c|}
\hline \multirow{2}{*}{ College } & \multicolumn{2}{|c|}{ Gender } & \multicolumn{4}{c|}{ Academic Rank } & \multirow{2}{*}{ DI } \\
\cline { 2 - 8 } & Male & Female & Lecturer & Assistant & Associate & Full & D \\
\hline Architecture & 2 & 0 & 0 & 0 & 1 & 1 & 0 \\
\hline $\begin{array}{l}\text { Arts and } \\
\text { Sciences }\end{array}$ & 4 & 5 & 0 & 0 & 2 & 7 & 3 \\
\hline $\begin{array}{l}\text { Agricultural } \\
\text { Sciences/Natural } \\
\text { Resources }\end{array}$ & 2 & 1 & 0 & 1 & 1 & 1 & 1 \\
\hline $\begin{array}{l}\text { Business } \\
\text { Administration }\end{array}$ & 3 & 1 & 0 & 0 & 3 & 1 & 2 \\
\hline $\begin{array}{l}\text { Education and } \\
\text { Human Sciences }\end{array}$ & 2 & 1 & 0 & 0 & 1 & 2 & 0 \\
\hline Engineering & 2 & 0 & 0 & 0 & 0 & 2 & 2 \\
\hline $\begin{array}{l}\text { Fine and } \\
\text { Performing Arts }\end{array}$ & 1 & 2 & 0 & 0 & 1 & 2 & 1 \\
\hline $\begin{array}{l}\text { Journalism } \\
\text { and Mass } \\
\text { Communication }\end{array}$ & 2 & 1 & 2 & 0 & 0 & 1 & 1 \\
\hline Total & 18 & 11 & 2 & 1 & 9 & 17 & 10 \\
\hline
\end{tabular}

NOTE: DI = direct involvement in the reform process, i.e., the individual served on one or more of the general education reform committees.

The reason for including both a homogeneous and heterogeneous sample was to determine the contextual and intervening conditions under which the emerging theory holds (Creswell, 2007). The final sample (see Table I) included a total of twenty-nine participants of all academic ranks as well as those who had a partial administrative appointment. The majority of the participants were tenured.

The primary form of data in this study consisted of one-on-one interviews with twenty-nine faculty who were involved in one way or another in the reform process. Overall, this study generated almost thirty hours of interview data, with the average interview lasting about one hour, ranging from twenty-two minutes to one hour and fifty-one minutes. The interview protocol consisted of a set of twenty initial open-ended questions that served as guiding questions during the open coding stage. Additional questions evolved as the interviewing process continued and the study moved into the axial and selective coding stages (Creswell, 2007). I also used the memoing technique to record thoughts in a journal, including impressions, observations, reflections, and interpretations, which played an important part in the development of the theory (Creswell, 2007). I continued to collect data until each emerging category was saturated and variation in the data was understood and addressed. The interviews were audio-recorded and 
transcribed verbatim. The coding and analysis of almost thirty hours of interviews were facilitated by MaxQDA, a qualitative text analysis software that allowed me to efficiently build a hierarchical code/category system that could quickly be changed or adjusted. It also let me keep track of emerging ideas and concepts by writing memos and attaching them to codes, categories, and sets of texts.

\section{Data Analysis and Coding Procedures}

Grounded theory requires several different stages of data analysis, including open coding, axial coding, and selective coding. In open coding, I developed categories of information about the general education reform process, axial coding connected the categories, and selective coding created a "story line" that connected the coding and the categories (Creswell, 2007). The goal was to elicit a substantive-level theory that speaks directly to the general education reform process at a doctoral/ research-extensive land-grant university. This approach emphasizes the concept of the explanatory power of the specific phenomenon as opposed to generalizing findings about a larger, more general theory (Strauss \& Corbin, 1998). The theory emerged from the data with the help of memoing and constant comparison, which is the process of taking information from data collection and comparing it to emerging categories (Creswell, 2007).

\section{Methods for Verification}

Several sources of data were used to build a "coherent justification for themes" (Creswell, 2007, p. 196), including interview data, extensive notes, and materials published by the institution about the new general education program. The themes that emerged were conveyed in categories and themes and illustrated with thick, rich verbatim detail of the participants' accounts of what happened, including negative and discrepant information. In addition, I conducted member checks by providing the participants with the theoretical paradigm that emerged during axial coding and a set of theoretical propositions for the purpose of soliciting their feedback. Eleven of the twenty-nine participants responded to the invitation to review the materials. Three of them indicated that the representation of findings seemed accurate but that they disagreed with the opinions of their colleagues.

\section{Findings}

\section{Open Coding}

During open coding, I examined the interview transcriptions and interview notes and created categories for the data, saturating each category until no new ones were needed to code all of the data. Five categories emerged, including 
process, environment, influencers, feelings, and effects. Each of the five categories had several subcategories and properties that represented multiple perspectives about the main categories, which helped to dimensionalize each. The properties included extreme possibilities on a continuum (Creswell, 2007).

\section{Axial Coding}

In axial coding, the data were assembled in new ways using six prescribed categories as suggested by Strauss and Corbin (1998). The purpose of labeling conditions was to tease out some of the "complex relationships among conditions and their subsequent relations to actions and interactions" (Strauss \& Corbin, I998, p. I3I). The data were placed into a new paradigm, including causal conditions, phenomenon, context, intervening conditions, strategies, and consequences. "Causal conditions" include events or happenings that influence the phenomenon, while "intervening conditions" alter the impact of causal conditions on the phenomenon. "Contextual conditions" are sets of conditions that create a set of circumstances to which individuals need to respond through actions and interactions. "Strategies" include actions and interactions that have a purpose and are deployed to resolve a problem, which, in turn, affects the phenomenon. "Consequences" refer to an action/interaction that is taken (or lack thereof), resulting in a variety of different effects that may alter the phenomenon. Strauss and Corbin's (1998) paradigm model suggests that when causal conditions exist and influence the phenomenon, the context and intervening conditions affect the strategies that are used to bring about certain consequences.

The theoretical model developed as a result of this study suggests that causal conditions (internal and external pressures) shape a phenomenon (phases of general education reform at a doctoral/research-extensive university), while the context (faculty buy-in, leadership, and timeline) as well as intervening conditions (institutional culture, campus politics, and the economic climate) influence the strategies (faculty involvement in the process and power of individuals) to bring about a set of consequences (a new outcomes-based general education program that is a reflection of the mission of a research-extensive university). The reform process is expressed graphically as a cycle (see Figure I) because the majority of the participants suggested that no general education program would ever be permanent and it would be revised after a certain number of years.

\section{Selective Coding}

Selective coding is the "process of integrating and refining the theory." Integration means that categories are interrelated and organized around a "central explanatory concept." The goal is to validate those relationships and to "fill in categories that 


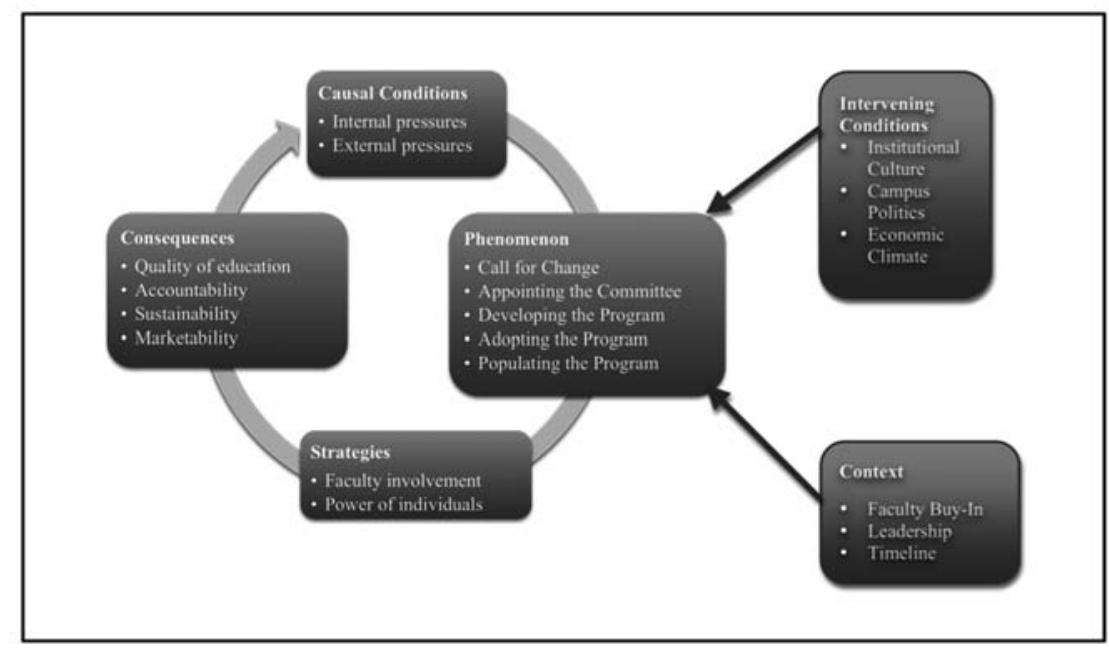

FIGURE I: Paradigm model of "phases of general education reform at a doctoral/ research-extensive university."

need further refinement and development" (Strauss \& Corbin, I998, p. I6I). Selective coding involved several steps that occurred simultaneously. The first step was to identify the central explanatory core category by asking "what the research is all about" (Strauss \& Corbin, 1998, p. 146). At this point the researcher is trying to determine the main problem with which the participants are grappling.

The central explanatory core category that emerged was "phases of general education reform at a doctoral/research-extensive university" and included five distinct phases. The central category emerged from the phenomenon ("phases of general education reform"), but during selective coding it became clear that participants differentiated between general education reform at a doctoral/researchextensive university as opposed to that at a smaller, liberal arts college, whose mission is typically less focused on research and more on teaching. All of the participants spoke about the fact that it was difficult to get involved in general education reform because they were engaged in other activities that are valued more at a research-extensive university, such as conducting research and bringing in grants. The central category indicates that general education reform at this particular university was highly influenced by the nature of the institution and mainly served as a cyclical process of revisiting and fine-tuning the institution's general education program in response to internal and external pressures.

After the central core category was identified, major categories were linked to it by identifying and stating how they related to the core. These two steps were accomplished by writing a story line that integrates the core explanatory category with the other major categories. The theory was then refined by "trimming off 
excess and filling in poorly developed categories" (Strauss \& Corbin, I998, p. I6I) and validated by comparing it against the data.

\section{The Story}

The causal conditions that affected the phases of general education reform at this particular doctoral/research-extensive university included both internal and external pressures and a perceived need by both faculty and administrators to create a more "user-friendly" general education program. External pressures such as assessment mandates, accreditation requirements, and competition from other institutions motivated the administration to call for a new general education program, while internal pressures such as a nonfunctioning, "unwieldy" previous general education program as well as transferability issues motivated faculty to entertain the thought of evaluating and perhaps changing the program.

The causal conditions and a failed attempt to revise the previous general education program set the parameters for the new curriculum. From the faculty perspective, the administration determined that the new program ought to be assessable while also simplifying the general education requirements for students so that the new program could support the university's recruitment and retention efforts. However, several intervening conditions affected the impact of the causal conditions on the new general education program. Faculty described the institutional culture at a large, land-grant, research-extensive university as one that values both research and teaching but rewards achievements in research more than achievements in undergraduate teaching. The focus on research, then, inhibited many faculty from participating more actively in the reform process. Instead, they relied on others to develop the program, to inform departments of the reform process, and at times to recommend whether to vote in favor of or against the program. Campus politics also affected the impact of the causal conditions. Although the faculty generally agreed that the previous general education program needed to at least be revised, they were concerned about the new program's impact on student credit hour production and subsequent funding. The economic climate was the third intervening condition. The lack of resources to support the new program emerged as the primary concern about the new general education program because faculty believed that funding was needed to (I) teach the new general education courses in small classes, (2) provide incentives for instructors to develop new general education courses, and (3) support meaningful assessment activities.

"The phases of general education reform at a doctoral/research-extensive university" include five distinct components: (I) calling for change, (2) appointing the committee, (3) developing the program, (4) adopting the program, and 
(5) populating the program. Although faculty were heavily involved in the last four phases of general education reform, the perception of the faculty was that it was administrators who called for a brand-new general education program using a top-down approach. They also noticed that the administration was actively involved in all five phases of the reform process. During the last four steps, several powerful individuals held key positions, some as representatives on one or more of the committees and others as independent promoters, facilitators, and communicators during various phases of the reform process.

Several contextual conditions affected the strategies that faculty used during the general education reform process. The property faculty buy-in ranged from low to high. Most faculty bought into the idea of general education reform but were disappointed by some decisions that were made that seemed to ignore faculty concerns. On the other hand, many faculty believed that they had plenty of opportunities to get involved in the process but decided to instead focus on other work the university rewarded more. They raised questions and voiced their concerns mostly during departmental meetings and trusted their unit's representative to speak on their behalf during general education reform meetings and open forums. As the level of faculty buy-in changed, so did their decision to vote for or against the program. Faculty buy-in was closely related to leadership as another contextual condition. Several leaders emerged during the process who were highly influential during the adoption phase of the new general education program. Finally, the aggressive timeline focused on getting the new program up and running much faster than most faculty would have liked. The result was a new general education program that achieved—at least on paper-the parameters that had been set by the causal conditions but which may have been compromised in terms of perceived quality of education.

Different levels of faculty involvement and the power of individuals were important strategies in the reform process to generate ideas, negotiate solutions, and implement the new program. Most faculty chose not to get involved, while others were just informed enough to vote either for or against the new program. Others were passionately involved in the process by sharing their opinions and voicing their concerns because they had a personal interest in general education. A small group of faculty was actively involved in the reform process because they were serving on one or more of the committees that developed/populated the program.

A new outcomes-based general education program rooted in AAC\&U's LEAP initiative was the main outcome that resulted from moving through the phases of general education reform at this particular doctoral/researchextensive university. Along with the main outcome, several consequences occurred as viewed by faculty. The quality of education was a consequence that faculty were concerned about first and foremost. Their opinions could 
be divided into two general groups, including faculty who felt strongly that the reform process increased the quality of education and those who believed that it lowered the quality. The faculty who believed that the quality of education would be improved tied their opinion to another consequence: the new program's assessibility. Although most faculty agreed that assessment is an important step in monitoring student learning, they questioned whether meaningful assessment at the course, program, and institutional level is possible both philosophically and practically. On the other end of the spectrum were those who believed that-despite best intentions— the new general education program inadvertently became the "lowest common denominator" in terms of the quality of learning, primarily because of the reduced number of required hours, the fact that a large percentage of certified general education courses could be taken in one's major, and the inability to keep all general education courses small with the institution's best instructors as teachers.

This perspective was related to another consequence: sustainability. Faculty recognized the limits of the new general education program as it was developed, adopted, and implemented and believed that those limits were the direct result of the lack of funding to support the new program financially. The motivation behind general education reform was different for faculty and administrators. While faculty were mostly concerned with their students' quality of education, they believed that administrators were motivated by another consequence: marketability. Marketability means creating a program that is conducive to student recruitment and retention, which, in turn, affects the university's ability to provide funding. Thus, the consequences of general education reform are interrelated and require sacrifices and compromises of different motivations and beliefs by those who are involved in the process if the goal is to create a new outcomesbased general education program at a doctoral/research-extensive, public university. Faculty viewed the reform process as cyclical, meaning that it has a life cycle that includes phases of development, adoption, implementation, growth, and decline, which eventually will lead to the next call for review and possibly change.

\section{Theoretical Propositions}

As a result of the theoretical model and the story line, a series of theoretical propositions was developed that explains how and why the general education reform process occurred at this doctoral/research-extensive university as perceived by faculty. The following theoretical propositions have been grounded in the data of this study:

I. From the faculty perspective, the general education reform process at a research-extensive, public university occurs in phases, including "calling 
for change," "appointing the committee," "developing the program," "adopting the program," and "populating the program."

I.I. The process is sequential in nature, meaning that one phase leads into the next, with some phases overlapping.

I.2. The process is cyclical in nature, meaning that it has a life cycle that eventually requires a new reform unless it can be flexible enough to allow the program to evolve.

I.3. The call for change is driven by the administration. Reform driven entirely by the faculty is inefficient.

I.4. A small committee consisting of faculty and administrators is appointed to generate a set of proposals for a new outcomes-based general education program. An advisory committee consisting of faculty and administrators is appointed to act as the liaison between the smaller colleges and the campus community. Not all colleges are necessarily represented.

I.5. Each college votes on the set of proposals in a two-step process. Each college must approve the proposals before the new program can be adopted.

I.6. A new committee consisting of faculty representatives from each college is appointed to populate the new general education program. Each representative must vote in favor of the course proposals before each course is considered "certified."

2. Based on faculty perception, faculty buy-in influences the phases of general education reform at a doctoral/research-extensive university.

2.I. Faculty who teach mostly undergraduate courses buy into general education reform more than faculty who teach mostly graduatelevel courses.

2.2. Nontenured faculty buy into general education reform less than tenured faculty.

2.3. If the reform process is perceived to be faculty-driven, faculty buy-in is larger than if it is perceived to be administration-driven.

2.4. If the new general education program is perceived to be an improvement over the previous program, faculty buy-in is larger.

2.5. If students buy into the new general education program, faculty are more likely to buy into it as well.

2.6. Faculty buy-in increases if respected and trusted colleagues ("change agents") are directly involved in the development.

2.7. Faculty buy-in decreases if administrators dominate the reform process. 
3. According to faculty, the leadership of key individuals shapes the phases of general education reform at a doctoral/research-extensive university.

3.I. The reform process will move through its phases when key administrators support but do not dictate the process.

3.I.I. If key administrators who have expertise in general education facilitate the different phases of general education reform, the probability of implementing a new general education program increases.

3.I.2. If key administrators dictate the parameters of the different phases of general education reform, the probability of implementing a new program decreases.

3.2. The reform process will move through its phases when key deliberating bodies, such as the Faculty Senate, the University Curriculum Committee, and the Academic Planning Committee, support the process.

3.2.I. If deliberating bodies assume a supporting role during the different phases of general education reform, the probability of implementing a new general education program increases.

3.2.2. If the deliberating bodies assume a developmental role during the different phases of general education reform, the probability of implementing a new general education program decreases.

3.3. The reform process will move through its phases when key faculty become involved in the process.

3.3.I. If the committees charged with developing and populating the new general education program include faculty who have broad expertise in the area and who have earned the trust and respect of their colleagues, the probability of implementing a new general education program increases.

3.3.2. Faculty who are not serving on either one of the committees but who have broad expertise in the area and who are well respected by their colleagues have the power to become change agents who can affect the vote positively or negatively.

3.4. The reform process will move through its phases when deans support but not dominate the process.

3.4.I. If academic deans encourage the reform process by appointing knowledgeable faculty to the developing and populating committees and by encouraging discussion of the reform process within their respective colleges, the probability of implementing a new general education program increases. 
3.4.2. If academic deans use their power to influence the faculty vote, faculty buy-in to the new program will decrease.

4. From a faculty perspective, the timeline of the general education reform process affects faculty feelings toward and buy-in to the reform process of the new general education program.

4.I. Administrators are unrealistic about setting an appropriate timeline for the different phases of general education reform, which influences how faculty feel about the process.

4.I.I. When the timeline is too aggressive during the development phase, faculty feel that their voices are not heard.

4.I.2. When the timeline is too aggressive during the adoption phase, faculty feel rushed into making a decision that is irreversible.

4.I.3. When the timeline is too aggressive during the population phase, faculty get frustrated because the time commitment to submit courses is too intense.

4.2. Faculty buy-in during the adoption phase increases when they believe that revisions can be made to proposals at a later time.

4.3. Faculty buy-in after the adoption phase decreases when the timeline is too short to allow adequate time for revisions and additional discussions.

5. According to faculty, institutional culture, campus politics, and the economic climate affect the phases of general education reform at a research-extensive, public university.

5.I. The institutional culture determines the way faculty and administrators engage in the general education reform process.

5.I.I. The mission of the institution affects the level of involvement of faculty in the reform process. If involvement in general education reform is not rewarded, faculty are less likely to participate in the process.

5.I.2. The level of collegiality among the undergraduate colleges influences the outcome of the general education process. The more collegial the culture, the higher the probability of developing, adopting, and populating the new program. The more managerial the culture, the lower the probability of developing, adopting, and populating the new program.

5.I.3. The colleges' respective governing structures provide the framework for developing, adopting, and populating the new program. 
5.2. Campus politics affect the general education reform process.

5.2.I. External politics such as the need to create a program that is compatible in terms of transferability of courses from other institutions in the state and to move students through the program efficiently influence the design and implementation of the program.

5.2.2. Internal politics such as territoriality among colleges and departments in terms of student credit hour production and other funding priorities influence the design and implementation of the program.

5.2.2.I. If colleges and departments perceive that they will lose student credit hours or other funding sources, they will protect their territory.

5.2.2.2. If colleges and departments protect their territory instead of focusing on the institutional interest, the probability of designing, adopting, and populating a new general education program will decrease.

5.3. The economic climate shapes the phases of the general education program reform process.

5.3.I. If the perceived need for general education reform is high, faculty are more willing to compromise on the quality of the new general education program.

5.3.2. If the perceived need for general education reform is high, the more likely faculty are to give up territoriality.

5.3.3. The more critical the financial situation, the less likely faculty are to engage in general education reform and the more likely they are to focus on research and bringing in grant funding.

5.3.4. The more critical the financial situation, the more likely colleges and departments are to engage in general education reform because they hope to gain financial resources.

6. Based on faculty perceptions, the power of key individuals affects the level of faculty involvement in the reform process, which is the strategy that is used to generate ideas, negotiate solutions, and implement a new general education program. There are four levels of involvement, including "no involvement," "passive, informed involvement," "active, informed involvement," and "active 'change agent' involvement."

6.I. At research-extensive, public universities most faculty are not actively involved in the reform process. 
6.2. At research-extensive, public universities quite a few faculty are passively involved in the reform process and trust key individuals' opinions when deciding how to vote.

6.3. At research-extensive, public universities a few faculty are actively involved in the reform process because they are personally interested in general education. These individuals may become change agents who affect other faculty in the voting decisionmaking process. They are more likely than any other group to distrust the administration and to be critical of the committees that are developing and populating the new program. If their voices are heard and acknowledged, the probability of adopting a new general education program increases.

6.4. At research-extensive, public universities a few key faculty are actively involved in the reform process by serving on one or more of the committees that are developing and/or populating the program. If they have earned the trust and respect of their colleagues, the probability of developing and adopting a new general education program increases.

7. According to faculty, the consequences of general education reform eventually evolve into internal and external pressures that will mark the end of the general education program's life cycle and require a new reform process.

7.I. If the general education program is not adequately funded, the quality of education, accountability, sustainability, and marketability of the program will erode.

7.2. If the general education program is adequately funded, its life cycle can be extended.

\section{Discussion and Conclusions}

This study fills an important gap in the literature, in that it provides a paradigm model of the general education reform process at a large, public, doctoral/ research-extensive university from the faculty perspective. One of the questions that remain is whether this particular reform process was successful. Many reform processes are seen as failures when they do not achieve the comprehensive change that reformers had originally planned (Kanter, Gamson, \& London, 1977). Arnold and Civian (1997) describe success in reform as a general education program that is better than what was in place before. They point out that many institutions complete the process but end up with a general education 
program that is not much different from the one they wanted to change. This was certainly a concern expressed by the participants in this study, particularly when the new general education program was seen in the context of specific colleges' additional distribution requirements. However, this study also shows that most participants agreed that the new program is fundamentally different from the one it replaced, in that it is an outcomes-based program that will be subject to accountability measures. In addition, the traditional subject-based silos of general education courses have been diminished. For example, whereas the English Department used to be the only department on campus that could provide general education writing courses, those courses can now be offered by any of the undergraduate colleges whose writing courses address all of the components of that particular general education student learning outcome.

Another question that remains is whether the reform process was worth the effort. The literature indicates that general education reform "can exhaust" an institution (Arnold \& Civian, 1997, p. 19). This study confirmed that in addition to financial and political costs, the reform process also incurs large amounts of human and organizational costs. The process started with a relatively small number of well-respected, very knowledgeable faculty and administrators who developed the new program. However, the costs increased dramatically after the new program was adopted and needed to be implemented. Although the faculty who reviewed the initial set of almost five hundred general education course proposals received monetary stipends for their work, many faculty spent an inordinate amount of time preparing course proposals, revising them, and tweaking existing courses' content to fit the criteria of the new general education program. Although it is too early to tell, many faculty were concerned that the assessment requirement at the course and program level will be the real test of whether the new general education program can be categorized as a "success" and whether the reform process was "worth the effort."

Whether or not faculty will declare the program itself a success after it has been in place for a few years remains to be seen. However, one thing that most of the participants agreed on was that the process was necessary and, for the most part, a positive experience. Although many faculty perceived the timeline of the reform process as being too aggressive, it kept the reform efforts moving. Combined with a highly effective communication plan and change agents who acted as opinion leaders in their colleges and departments, the timeline contributed to the completion of the process. However, the results of this study indicate that for faculty at this particular university, completion of the process is not enough. Many of the participants saw the new general education program as a compromise of developing and implementing an outcomes-based general education program while at the same time jeopardizing the quality of the education as a result. 
Financial backing of the reform process and the new general education program as a result of the process continues to be a challenge at most universities. This study confirmed that faculty are generally concerned with the lack of funding for general education programs. On the faculty wish list are small first-year seminars taught only by the best instructors the university has. They also tended to ask for additional faculty lines as well as resources for faculty development related to assessment of student learning. In addition, faculty often would like to have additional administrative support to direct the program itself as well as to assess it in order to ensure sustainability (Ferren \& Kinch, 2003). At this particular institution faculty were no different, but here any additional resources would primarily go to the assessment of the courses. While funding is indeed an important concern in general education reform, Ferren and Kinch argue that resources cannot buy everything. For example, they state that one of the most important obstacles to overcome is student resistance to the new program. Faculty need to explain what general education is and how it benefits students. They need to motivate students to do well in general education courses because "the real dollar cost to the institution is apparent when students repeat a failed course or take their tuition dollars to the local community college to fulfill a dreaded requirement" (Ferren $\&$ Kinch, 2003, p. Io). One of the consequences of the reform process that emerged from this study was the emphasis on the marketability of the new program over its other characteristics. This study confirms Arnold and Civian's (1997) finding that administrators often like to use a new general education program as a recruiting tool.

Finally, this study echoes previous findings about teaching general education courses. Cuban (1999) suggests that the structure of a doctoral/researchextensive university makes it more difficult for faculty to get involved in curricular change, primarily because research is more rewarded and valued than teaching. As Dubrow (2004) says, "Within the university, the main cogs in the teaching wheel, professors, are hired to teach but rewarded to research. Good and renowned research is a major source of financial and affective rewards for the institution. Teaching is not" (p. II2). However, whereas Cuban argues that general education reform at a research-extensive university tends to result in modest change, this study suggests that fundamental change may be possible. Although the program itself may appear similar to the previous one to some, the fundamental change is that it is now assessable and more accountable. Whether the assessment will be meaningful and result in more effective student learning of the outcomes should be investigated in future studies.

Arnold and Civian (1997) note that general education reform will not cover up uninspired teaching even if the curriculum itself is improved. The 
reform process at this particular university focused primarily on developing the curriculum and less on the quality of teaching. This study showed that many faculty recognized this issue and continued to be concerned about it. However, "pedagogical innovations are costly, and resource-dependent institutions, in particular, experience difficulties finding the funds for such innovations" (Arnold \& Civian, 1997, p. 22). This is one area that this particular institution did not necessarily plan for in the developing stages of the reform process, which could handicap the new general education program in the long run and shorten its life cycle. Arnold and Civian warn that inconsistent quality of teaching in any general education program will send inconsistent symbolic messages to stakeholders, including students, parents, and employers. However, this potential challenge can become an opportunity if the institution decides to have its best professors teach general education courses, to provide funding to improve teaching, and to keep classes small enough so that students can actively engage in learning. Speaking from a marketing perspective, this particular institution has a real opportunity to brand its new general education program as one of the first high-quality, outcomes-based general education programs in the country that provides the core of knowledge for undergraduate students at a doctoral/research-extensive, public institution.

\section{Limitations}

This study is limited to the perspectives of faculty about general education reform at one public, doctoral/research-extensive university. One unexpected limitation was that many faculty who were not involved in the reform process were unable to participate in the study because they felt that they did not have anything to contribute. Therefore, I had to recruit individuals who were involved in the reform process either because they served on one of the official general education reform committees or because they were otherwise integrally involved in curriculum development in their respective colleges, either as department chairs or as representatives on a curriculum committee. Another limitation is that the study was focused only on faculty perceptions of the reform process. Individual participants sometimes had difficulty remembering facts and exact procedures. Finally, the substantive-level theory that emerged from this study can be generalized only to the subjects of the study but not to a broad population because of the purposeful, theoretical sampling frame.

\section{Recommendations for Future Research}

While this study adds to the existing literature about the process of general education reform by providing the faculty perspective, one voice that is not often 
heard is that of the students, who are ultimately affected by the decisions that are made about their education. Therefore, additional research that focuses on the perception of students would be helpful, especially as student engagement in a new general education program has been identified as one of the most important determinants of success (Ferren \& Kinch, 2003). In addition, the theoretical propositions that emerged from the results of this qualitative study should be tested quantitatively among a larger sample of faculty at this particular institution as well as other doctoral/research-extensive, public institutions that are embarking on a similar general education reform process.

One of the themes that emerged from this study was that faculty described the level of collegiality among members of the developing committee as well as the populating committee as a major reason why the reform process and its implementation occurred in a relatively short time frame. Future research should explore how similar committees function and how members relate to each other, respond to conflict, and negotiate solutions. A new study could focus in more depth on the group dynamics of the different committees to better understand the development process from the perspective of committee members.

Finally, a large part of this study focused on the implementation of a new outcomes-based general education program as participants tried to predict its performance. Although it was perhaps too early for them to comment on what might happen in the future, the effects of the new program should be measured after it has been implemented for a few years and the first cycle of institutional assessment has been completed. The results of such a study, when combined with the results of this study, could provide a longitudinal perspective of general education reform at a public, doctoral/research-extensive university in the United States.

\section{NOTE}

I. The phrase "developmental role" refers to any direct involvement in the reform process, such as developing the specific language of student learning outcomes, writing governing procedures, etc.

\section{References}

Arnold, G., \& Civian, J. (1997). The ecology of general education reform. Change, 29(4), I8-23.

Association of American Colleges and Universities. (2007). College learning for the new global century. Washington, D.C.: Author.

Baxter Magolda, M. B. (1999). Creating contexts for learning and self-authorship: Constructivedevelopmental pedagogy. Nashville: Vanderbilt University Press.

Black Duesterhaus, M. (2003). General education in higher education. In J. W. Guthrie (Ed.), Encyclopedia of education, 3 (2nd ed.; pp. 923-25). New York: Macmillan Reference. 
Retrieved September Io, 2009, from Gale Virtual Reference Library via Gale, http://o-go. galegroup.com.library.unl.edu/ps/start.do?p=GVRL\&u=linc74325.

Conrad, C. F. (1978). The undergraduate curriculum: A guide to innovation and reform. Boulder: Westview Press.

Creswell, J. W. (2005). Educational research: Planning, constructing, and evaluating quantitative and qualitative research (2nd ed.). Upper Saddle River, N.J.: Pearson Education.

Creswell, J. W. (2007). Qualitative inquiry and research design: Choosing among five approaches. Thousand Oaks: Sage Publications.

Cuban, L. (1999). How scholars trumped teachers: Change without reform in university curriculum, teaching, and research, I890-1990. New York: Teachers College Press.

DeZure, D. (2003). Innovations in the undergraduate curriculum. In J. W. Guthrie (Ed.), Encyclopedia of education, 2 (2nd ed.; pp. 509-24). New York: Macmillan. Retrieved September I0, 2009, from Gale Virtual Reference Library via Gale, http://o-go.galegroup. com.library.unl.edu/ps/start.do?p=GVRL\&u=linc74325.

Dressel, P. L. (1968). College and university curriculum. Berkeley: McCuthan.

Dubrow, G. (2004). Collegiality and culture: General education curriculum reform at Western Protestant University. JGE: The Journal of General Education, 53(2), I07-34.

Ferren, A., \& Kinch, A. (2003). The dollars and sense behind general education reform. Peer Review, 5(4), 8-II.

Hart Research Associates. (2009, May). Trends and emerging practices in general education. Based on a survey among members of the Association of American Colleges and Universities. Retrieved January 15, 20I2, from http://www.aacu.org/membership/ documents/2009MemberSurvey_Part2.pdf.

Kanter, S., Gamson, Z., \& London, H. (1977). Revitalizing general education in a time of scarcity: A navigational chart for administrators and faculty. Boston: Allyn and Bacon.

Kean, R., Mitchell, N., \& Wilson, D. E. (2008). Toward intentionality and transparency: Analysis and reflection on the process of general education. Peer Review, Io(4), 4-8.

Kotter, J. P. (1998). Leading change: Why transformation efforts fail. Harvard Business Review, 73(2), 59-67.

Mentkowski, M., \& Associates. (2000). Learning that lasts: Integrating learning, development, and performance in college and beyond. San Francisco: Jossey-Bass.

Noll, C. (200I). Change process. In B. S. Kaliski (Ed.), Encyclopedia of business and finance, $I$ (pp. I25-28). New York: Macmillan. Retrieved October 6, 2009, from Gale Virtual Reference Library via Gale, http://o-go.galegroup.com.library.unl.edu/ps/start. do? $\mathrm{p}=\mathrm{GVRL} \& \mathrm{u}=$ linc 74325 .

Rhodes, F. H. T. (2003). The creation of the future: The role of the American university. Ithaca: Cornell University Press.

Ropers-Huilman, B. (1998). Feminist teaching in theory and practice: Situating power and knowledge in poststructural classrooms. New York: Teachers College Press.

Strauss, A., \& Corbin, J. (1998). Basics of qualitative research: Techniques and procedures for developing grounded theory (2nd ed.). Newbury Park, Calif.: Sage.

Taba, H. (1962). Curriculum development: Theory and practice. New York: Harcourt, Brace, and World.

Tierney, W. G. (1988). Organizational culture in higher education: Defining the essentials. Journal of Higher Education, 59(I), 2-2I.

Tyler, R. W. (1949). Basic principles of curriculum and instruction. Chicago: University of Chicago Press. 
Copyright of JGE: The Journal of General Education is the property of Pennsylvania State University Press and its content may not be copied or emailed to multiple sites or posted to a listserv without the copyright holder's express written permission. However, users may print, download, or email articles for individual use. 